\title{
Impact of comorbidities and drug therapy on development of renal impairment in a predominantly African American and Hispanic HIV clinic population
}

This article was published in the following Dove Press journal:

HIV/AIDS-Research and Palliative Care

26 January 2011

Number of times this article has been viewed

\author{
M Keith Rawlings' \\ Jennifer Klein' \\ Edna P Toubes Klingler' \\ Ejeanée Queen' \\ Lauren Rogers' \\ Linda $\mathrm{HYau}^{2}$ \\ Keith A Pappa ${ }^{2}$ \\ Gary E Pakes ${ }^{2}$ \\ 'AIDS Arms Peabody Health Clinic, \\ Dallas, Texas; ${ }^{2}$ GlaxoSmithKline, \\ Research Triangle Park, North \\ Carolina, USA
}

\begin{abstract}
Purpose: Renal impairment in human immunodeficiency virus (HIV)-infected patients could potentially be caused by many factors. HIV-related renal impairment risks have been little studied in African Americans and Hispanics. We investigated the impact of HIV itself, highly active antiretroviral therapy (HAART), comorbidities, and non-HIV-related drug treatment on glomerular filtration rate in a predominantly African American/Hispanic HIV-infected population who had received HAART for at least one year. This study was a retrospective electronic medical record database evaluation of renal impairment risks in a largely African American/Hispanic HIV population obtaining medical care at an HIV clinic in Dallas, Texas.
\end{abstract}

Methods: Proportional hazards models were used to investigate an association between an estimated glomerular filtration rate decrease $>25 \%$ from baseline (ie, renal impairment) and demographics, antiretroviral/nonantiretroviral medications, comorbidities (hypertension, diabetes mellitus, hepatitis $\mathrm{C}$ virus [HCV] infection, hepatitis $\mathrm{B}$ virus [HBV] infection), CD4+ counts, viral load, and duration patients were monitored at the clinic (time on study).

Results: In total, 323 patients were evaluated: 82\% males; 61\% African American/12\% Hispanic/19\% Caucasian; mean age 37.9 years (standard deviation [SD] 8.5); 6\% HBVpositive; $34 \% \mathrm{HCV}$-positive; $29 \%$ hypertensive; $3 \%$ diabetic; $52 \%$ tenofovir-treated; mean weight $75.4 \mathrm{~kg}$ (SD, 15.4); mean estimated glomerular filtration $114.5 \mathrm{~mL} / \mathrm{min} / 1.73 \mathrm{~m}^{2}$ (SD, 36.7) using the Modification of Diet in Renal Disease (MDRD) calculation method; mean creatinine clearance (from which estimated glomerular filtration was extrapolated) by the Cockcroft-Gault calculation method $120.6 \mathrm{~mL} / \mathrm{min} / 1.73 \mathrm{~m}^{2}$ (SD, 41.2); mean time on study 2.7 years (SD, 1.0 year). An estimated glomerular filtration rate decrease of $>25 \%$ from baseline was significantly associated with time on study ( $P=0.0017$; hazards ratio $[\mathrm{HR}]=0.999)$ and hypertension $(\mathrm{HR}=1.706 ; P=0.0158)$ by the MDRD method, and with age $(\mathrm{HR}=1.039 ; P=0.0077)$, weight $(\mathrm{HR}=0.987 ; P=0.0023)$, and time on study $(\mathrm{HR}=0.999 ; P=0.0043)$ by extrapolation of Cockcroft-Gault creatinine clearance calculation. No specific HAART agent was associated with significant renal impairment risk by the definition used in this study.

Conclusion: This retrospective database study showed time on study, hypertension, weight, and age to be the only significant predictors of an estimated glomerular filtration rate decrease $>25 \%$ from baseline.

Keywords: nephropathy, antiretroviral therapy, comorbidities, tenofovir, African American, Hispanic
Correspondence: M Keith Rawlings Peabody Health Clinic, 1906 Peabody Avenue, Dallas, TX 75215, USA

$\mathrm{Tel}+\mathrm{I} 2$ I 4 42I 7848

Fax + I 214421 III

Email krawlings@aidsarms.org submit your manuscript | www.dovepress.com

Dovepress

DOI: 10.2147/HIV.SI 3902
HIVIAIDS - Research and Palliative Care 20II:3 I-8

(C) 20II Rawlings et al, publisher and licensee Dove Medical Press Ltd. This is an Open Access article which permits unrestricted noncommercial use, provided the original work is properly cited. 


\section{Introduction}

Because highly active antiretroviral treatment (HAART) has transformed human immunodeficiency virus (HIV) infection from a progressively deteriorating fatal disease to a long-term, controllable condition, an increasing number of HIV-infected patients are living to an advanced age. As a consequence, these patients are being diagnosed with chronic diseases that contribute to renal impairment, including hypertension, atherosclerotic cardiovascular disease, and diabetes mellitus. ${ }^{1,2}$ Kidney function has been reported to be abnormal in up to $30 \%$ of HIV-infected patients. ${ }^{3}$ African Americans comprise nearly one-half ( $48 \%$ ) of all US HIV/autoimmune deficiency syndrome (AIDS) cases, acquire HIV infection at seven times the rate of Caucasians, and are nearly twice as likely to have diabetes mellitus. ${ }^{4,5}$ Thus, they appear more predisposed than Caucasians to developing HIV-associated nephropathy ( $90 \%$ of all reported cases) and cardiovascular disease. $^{6-9}$

Hispanics account for $17 \%$ of US HIV/AIDS cases and have a 2.5-fold higher rate of acquiring new HIV infections compared with nonHispanic Caucasians. ${ }^{10}$ Because Hispanics more frequently have diabetes and experience more diabetes-related end-stage renal disease than non-Hispanic Caucasians, ${ }^{10-12}$ they would in theory be at greater risk of worsening renal function if given antiretroviral drugs that adversely affect the glomeruli or proximal tubules or which exacerbate diabetes by inducing insulin resistance.

Many studies have been performed to evaluate risk factors that may contribute to renal impairment or renal failure in HIV-infected patients. ${ }^{13-27}$ Some have linked certain antiretroviral drugs, especially tenofovir disoproxil fumarate (TDF) and the protease inhibitors lopinavir/ritonavir, atazanavir/ritonavir, indinavir and saquinavir/ritonavir, with reduction in estimated glomerular filtration rate (eGFR) and renal tubular abnormalities. ${ }^{28,29}$ Few of these studies have examined populations in which the majority of patients are African American or Hispanic. Most renal risk assessments have used the Cockcroft-Gault (CG) method of calculating creatinine clearance $(\mathrm{CrCl})$, from which a value for eGFR can be extrapolated..$^{30}$ The CG-estimated eGFR incorporates body weight and gender. It may be less accurate than the Modification of Diet in Renal Disease (MDRD) method, ${ }^{31}$ which has adjustment factors for female gender and African American race. The purpose of the current study was to evaluate the relationship between demographics, antiretroviral/ nonantiretroviral medication, comorbidities, duration of HIV, duration of HAART, viral load, and CD4+ cell counts on the development of a $>25 \%$ reduction in eGFR, as estimated by both the CG and MDRD equations, in a predominantly African American and Hispanic outpatient HIV clinic population.

\section{Methods}

This retrospective, single-center, Phase IV electronic database study was conducted at the AIDS Arms Peabody Health Center in Dallas, Texas, a large outpatient HIV clinic that services the health care needs of a primarily African American and Hispanic HIV population. Medical records of 691 clinic patients followed for up to four years (2003-2008) were reviewed. Data that were collected from these records and tabulated included demographics, laboratory values, viral load, CD4+ cell count, comorbidities (hypertension, diabetes mellitus, anemia, hepatitis C [HCV], and HBV), history of antiretroviral and nonantiretroviral drugs received (with start, stop and change dates), and medication adherence history as assessed by prescription refill records. Nucleoside reverse transcriptase inhibitors for which usage data were available included zidovudine, stavudine, didanosine, lamivudine, abacavir, TDF, emtricitabine, the lamivudinezidovudine fixed-dose combination tablet, the abacavirlamivudine-zidovudine fixed-dose combination tablet, the TDF-emtricitabine fixed-dose combination tablet, and the abacavir-lamivudine fixed-dose combination tablet. Usage data were also available for the non-nucleoside reverse transcriptase inhibitors efavirenz, nevirapine, and delavirdine, and for the protease inhibitors atazanavir, nelfinavir, lopinavir/ritonavir, fosamprenavir, saquinavir, indinavir, and ritonavir. Package inserts for antiretroviral agents were consulted before these agents were prescribed to ensure appropriate dosing regimens based on baseline laboratory tests. No special renal function requirements outside of product labeling were applied for any individual antiretroviral, including TDF. Data were analyzed only for HAART-treated patients who had been monitored continuously at the Peabody Health Center for at least one year, comparing disease treatment characteristics of patients whose eGFR fell by more than $25 \%$ from baseline with those having no eGFR change.

The eGFR was assessed two ways. First, it was estimated from $\mathrm{CrCl}$ values calculated by the $\mathrm{CG}$ formula: ${ }^{30}$

$$
\mathrm{CrCl}=\frac{[(140-\text { age }) \times \text { body weight }]}{(\text { Serum creatinine } \times 72)} \times 0.85(\text { if female })
$$

where $\mathrm{CrCl}$ is expressed in $\mathrm{mL} / \mathrm{min}$, age in years, weight in kilograms, and serum creatinine in $\mathrm{mg} / \mathrm{dL}$. Second, eGFR was calculated by the MDRD formula: ${ }^{31}$ 


$$
\begin{aligned}
\mathrm{eGFR}= & 186.3 \times(\text { serum creatinine })^{-1.154} \times(\text { age in years })^{-0.203} \\
& \times 1.212(\text { if African American }) \times 0.742(\text { if female })
\end{aligned}
$$

Study endpoints included time from HAART initiation to event (eGFR decreasing by $>25 \%$ from baseline) in the entire study group and the TDF-treated versus nonTDF-treated subgroups, and the effect of comorbidities and concomitant antiretroviral and nonantiretroviral medications on time to $>25 \%$ decrease in eGFR from baseline. Statistical analyses were primarily descriptive, although a proportional hazards model was used to analyze time to event (calculated $>25 \%$ eGFR decrease from baseline), with subanalysis of TDF-treated versus non-TDF-treated patients.
Variation in treatment duration and other variables that could possibly contribute to renal impairment were factored into the model building process. Statistical analysis was performed by MDC-Biomed Data Sciences-ID at GlaxoSmithKline.

\section{Results}

Data from a total of 323 patients who had been treated with HAART for at least one year were evaluated (Table 1). Most $(82 \%)$ were males, and the racial/ethnic distribution was 61\% African American, 19\% Caucasian, 12\% Hispanic, and $8 \%$ other. Mean age was 37.9 years, and mean weight was $75.4 \mathrm{~kg}$. Of the comorbidities examined, about onethird of the patients were HCV-positive (34\%), 29\% were

\begin{tabular}{|c|c|c|c|}
\hline & $\begin{array}{l}\text { TDF+ } \\
\mathbf{n}=167\end{array}$ & $\begin{array}{l}\text { TDF- } \\
n=156\end{array}$ & $\begin{array}{l}\text { Total } \\
n=323\end{array}$ \\
\hline \multicolumn{4}{|l|}{ Gender, n (\%) } \\
\hline Female & $38(23 \%)$ & $21(13 \%)$ & $59(18 \%)$ \\
\hline Male & $129(77 \%)$ & 135 (87\%) & $264(82 \%)$ \\
\hline \multicolumn{4}{|l|}{ Age, years } \\
\hline Mean (SD) & $37.4(8.0)$ & $38.4(9.0)$ & $37.9(8.5)$ \\
\hline \multicolumn{4}{|l|}{ Race, $\mathrm{n}(\%)^{\mathrm{b}}$} \\
\hline Black & $96(57 \%)$ & 102 (65\%) & $198(61 \%)$ \\
\hline White & $4 \mathrm{I}(25 \%)$ & $21(13 \%)$ & $62(19 \%)$ \\
\hline Hispanic & $19(11 \%)$ & $21(13 \%)$ & $40(12 \%)$ \\
\hline Other & II (7\%) & $12(8 \%)$ & $23(7 \%)$ \\
\hline \multicolumn{4}{|c|}{ HIV-I RNA ( $\log _{10}$ copies/mL) } \\
\hline Median (range) & $3.96(1.69-5.75)$ & $3.74(1.69-5.87)$ & $3.86(1.69-5.87)$ \\
\hline \multicolumn{4}{|c|}{ CD4 cell count (cells $\left./ \mathrm{mm}^{3}\right)$} \\
\hline Median (range) & $298(8-1664)$ & $430(4-1694)$ & $343(4-1694)$ \\
\hline \multicolumn{4}{|l|}{ Weight (kg) } \\
\hline Mean (SD) & 75.1 ( 15.3$)$ & $75.6(15.6)$ & $75.4(15.4)$ \\
\hline \multicolumn{4}{|l|}{ Hepatitis B status } \\
\hline Positive & $13(8 \%)$ & $6(4 \%)$ & $19(6 \%)$ \\
\hline \multicolumn{4}{|l|}{ Hepatitis C status } \\
\hline Positive & $57(34 \%)$ & $54(35 \%)$ & I I | (34\%) \\
\hline \multicolumn{4}{|l|}{ Hypertension } \\
\hline Yes & $50(30 \%)$ & $44(28 \%)$ & $94(29 \%)$ \\
\hline \multicolumn{4}{|l|}{ Diabetes } \\
\hline Yes & $\mathrm{I}(<\mathrm{l} \%)$ & $10(6 \%)$ & II (3\%) \\
\hline \multicolumn{4}{|c|}{ Cockcroft-Gault $\mathrm{CrCl}$ category (mL/min) } \\
\hline$<30$ & 0 & $\mathrm{I}(<\mathrm{I} \%)$ & $\mathrm{I}(<\mathrm{I} \%)$ \\
\hline $30-60$ & 2 (I\%) & $3(2 \%)$ & $5(2 \%)$ \\
\hline$\geq 60$ & 140 (84\%) & |3| (84\%) & 271 (84\%) \\
\hline Missing & $25(15 \%)$ & $21(13 \%)$ & $46(14 \%)$ \\
\hline Mean (SD) & $120(45.6)^{*}$ & $121.2(36.2)^{\ddagger}$ & $120.6(4 \mid .2)^{\|}$ \\
\hline \multicolumn{4}{|c|}{ MDRD GFR category (mL/min) } \\
\hline$<30$ & 0 & $\mathrm{I}(<\mathrm{I} \%)$ & $\mathrm{I}(<\mathrm{I} \%)$ \\
\hline $30-60$ & $\mathrm{I}(<\mathrm{I} \%)$ & $\mathrm{I}(<\mathrm{I} \%)$ & $2(<1 \%)$ \\
\hline$\geq 60$ & 143 (86\%) & I 34 (86\%) & $277(86 \%)$ \\
\hline Missing & $23(14 \%)$ & $20(13 \%)$ & 43 (I3\%) \\
\hline Mean (SD) & I I4 (44.4) & II $5(26.4)^{\S}$ & I I $4.5(36.7)^{\pi}$ \\
\hline
\end{tabular}

Table I Baseline characteristics by tenofovir (TDF) status for antiretroviral therapy-exposed patients at least one year on study

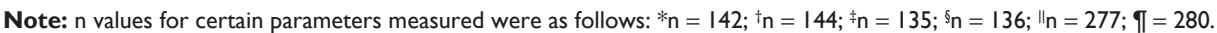

Abbreviations: $\mathrm{CrCl}$, creatinine clearance; GFR, glomerular filtration rate; MDRD, modification of diet in renal disease; SD, standard deviation. 
hypertensive, $6 \%$ were $\mathrm{HBV}$-positive, and 3\% were diabetic. Fifty-two percent had been TDF-treated and 48\% nonTDF-treated. Mean baseline MDRD-assessed eGFR was $114.5 \mathrm{~mL} / \mathrm{min} / 1.73 \mathrm{~m}^{2}$; and mean CG-assessed eGFR was $120.6 \mathrm{~mL} / \mathrm{min} / 1.73 \mathrm{~m}^{2}$. The mean ( \pm standard deviation [SD]) time on study for HAART-exposed patients monitored for at least one year was the same in the TDF-treated and nonTDF-treated groups (2.7 years [SD, 1.0 year]). The mean time patients were specifically exposed to TDF-based HAART was 1.8 years ( $\mathrm{SD}, 1.3$ years), and the time patients were exposed to non-TDF-based HAART was 1.7 years (SD, 1.3 years).

Using CG-assessed eGFR, proportional hazards analysis showed age, weight, and time on study significantly predicted a $>25 \%$ decline from baseline in eGFR (Table 2). For each year of increase in age at baseline, the hazard of having a $>25 \%$ decline from baseline in CG eGFR increased by $3.9 \%$. For each unit increase in weight, the hazard of having a $>25 \%$ decline from baseline in CG eGFR decreased by $1 \%$, and for each additional day in the study, it decreased by $0.1 \%$. Using MDRD-calculated eGFR, proportional hazards analysis showed that time on study and a diagnosis of hypertension at baseline significantly predicted a $>25 \%$ eGFR decline (Table 2). For each additional day in the study, the hazard of having a $>25 \%$ decline from baseline in MDRDassessed eGFR decreased by $0.1 \%$. Patients with a diagnosis of hypertension at baseline were 1.7 times more likely to have a $>25 \%$ decline from baseline in MDRD eGFR than those who were not hypertensive at baseline.

Factors that did not show a significant predictive value of a $>25 \%$ decline by either method of assessing eGFR were type of antiretroviral/nonantiretroviral medications coadministered, certain comorbidities (HCV and HBV infection), and the magnitude of CD4+ counts and viral load. Because only $3 \%$ of the patients were diabetics, too few were involved to allow a risk factor analysis of a diagnosis of diabetes mellitus on renal function.

\section{Discussion}

Studies of renal impairment risks in antiretroviral-treated HIV patients have reported discordant results, possibly due to differences between studies in the definition of renal impairment applied, racial proportions evaluated, laboratory values monitored, size of populations examined, duration over which patients were assessed or had received HAART, types of HAART agents used, and inclusion of patients with baseline low eGFR in some studies but not others. ${ }^{13-27}$ Renal risk factors in a predominantly African American/Hispanic HIV population have undergone limited study to date, despite these populations having a faster rate of acquiring HIV infection relative to other racial or ethnic groups. ${ }^{6,10,32,33}$

Our retrospective database study in a primarily (73\%) African American or Hispanic HIV cohort showed that time on study, hypertension, weight, and age were the only significant predictors of an eGFR decrease $>25 \%$ from baseline, and that TDF or any other specific antiretroviral agent or combination used, other comorbidities, baseline viral load, and baseline CD4+ count did not affect this endpoint. Our finding that increased time on study (and, hence, on HAART) was associated with a decline in renal function is at odds with what has been reported in several case reports and studies in which eGFR either improved or HIV-associated nephropathy progression slowed after HAART initiation. ${ }^{34-38}$ A reason for this discrepancy may stem from our population having had a higher mean baseline eGFR $\left(120.6 \mathrm{~mL} / \mathrm{min} / 1.73 \mathrm{~m}^{2}\right.$ by CG estimation and $114.5 \mathrm{~mL} / \mathrm{min} / 1.73 \mathrm{~m}^{2}$ by MDRD) compared with the HIV populations in whom improved renal function has been reported after HAART initiation. This reason is corroborated by data from the large Centers for AIDS Research Network of Integrated Clinical Systems $(n=4770)$, which showed that one year after HAART was started in previously treatment-naïve patients, MDRD-assessed eGFR improved in patients with chronic kidney disease at baseline $\left(\mathrm{eGFR}<60 \mathrm{~mL} / \mathrm{min} / 1.73 \mathrm{~m}^{2}\right)$, but decreased in patients with

Table 2 Summary of proportional hazards model for Cockcroft-Gault CrCl and MDRD-calculated GFR using stepwise selection method in antiretroviral therapy-exposed patients at least one year on study

\begin{tabular}{llll}
\hline Variable $(\mathbf{n}=\mathbf{1 6 2})$ & Parameter estimate (SD) & P value & Hazard ratio \\
\hline CG method & $0.0136(0.0019)$ & & 1.014 \\
CG-estimated CrCl & $0.0381(0.0143)$ & 0.0001 & 1.039 \\
Age, years & $-0.0128(0.0042)$ & 0.0077 & 0.987 \\
Weight (Ibs) & $-0.0013(0.0004)$ & 0.0043 & 0.999 \\
Time on study (days) & & & 1.012 \\
MDRD method & $0.0120(0.0016)$ & $<0.0001$ & 0.999 \\
MDRD-estimated GFR & $-0.0012(0.0004)$ & 0.0017 & 1.706 \\
Time on study (days) & $0.5342(0.2213)$ & 0.0158 & \\
Hypertension & P & & \\
\hline
\end{tabular}

Abbreviations: $\mathrm{CrCl}$, creatinine clearance; GFR, glomerular filtration rate; MDRD, modification of diet in renal disease; SD, standard deviation; CG, Cockcroft-Gault. 
initially normal renal function. ${ }^{39}$ Another factor that might explain the decrease rather than increase in renal function in our patient population is the fact that our study included a large proportion of African Americans, and the latter have a much faster rate of progression to end-stage renal disease than do Caucasian populations, thus making the decrements in eGFR in our African American cohort likely to outweigh increments in other study patients. ${ }^{40}$

In a larger study involving primarily African American patients from the Philadelphia area $(n=500 ; 67 \%$ African American), Short et $\mathrm{al}^{21}$ similarly found over one year that TDF therapy did not cause a significant change in MDRDestimated eGFR compared with a non-TDF-treated control arm, and that gender and diabetes were not risk factors for renal impairment. However, unlike our study, these investigators saw a significant increase in eGFR in patients receiving non-TDF-containing regimens, and found that hypertension, weight, or age did not confer greater renal impairment risk.

In one other renal risk study in a predominantly African American population (89\% African American, 28\% treatmentnaïve, mean HAART exposure 16 months), ${ }^{17}$ multivariate regression analysis showed diabetes, hyperlipidemia, baseline MDRD-calculated eGFR $>90 \mathrm{~mL} / \mathrm{min} / 1.73 \mathrm{~m}^{2}$, and TDF use were associated with greater decreases in eGFR. TDF effects remained significant at six months $(P<0.05)$ and at the end of therapy $(P=0.05)$ after adjustment for age and baseline eGFR. A subgroup comparison of TDF-treated patients $(n=150)$ and abacavir-treated patients $(n=68)$ showed that $17 \%$ of the TDF group and $9 \%$ of the abacavir group experienced an eGFR decrease $>30 \mathrm{~mL} / \mathrm{min} / 1.73 \mathrm{~m}^{2}$, and that change in eGFR at one year was greater with TDF (-11.48 versus $-3.91 \mathrm{~mL} / \mathrm{min} / 1.73 \mathrm{~m}^{2}$ for abacavir). Our study included 110 patients who had taken abacavir as part of HAART regimens for at least one year, and baseline mean eGFR did not differ between patients on abacavir (CG-estimated: $121 \mathrm{~mL} / \mathrm{min} / 1.73 \mathrm{~m}^{2}$; MDRD: $113.7 \mathrm{~mL} / \mathrm{min} / 1.73 \mathrm{~m}^{2}$ ) and the 167 patients on TDF (CG-estimated: $120.0 \mathrm{~mL} / \mathrm{min} / 1.73 \mathrm{~m}^{2}$; MDRD-estimated: $114 \mathrm{~mL} / \mathrm{min} / 1.73 \mathrm{~m}^{2}$ ), with over $80 \%$ of patients in each group having a baseline eGFR $\geq 60 \mathrm{~mL} / \mathrm{min} / 1.73 \mathrm{~m}^{2}$ by either calculation method (data not shown). As we found with TDF, use of abacavir was not associated with our particular endpoint, ie, an increased risk of $>25 \%$ decrease in eGFR. However, it is of note that our study was not powered to compare TDF regimens with abacavir regimens regarding renal function change.

The renal impairment risk factors we observed in a predominantly African American/Hispanic cohort are comparable with those reported in US or European studies in large HIV-infected Caucasian populations and in studies in black patients in Africa. ${ }^{13-16,18-20,22-27,29,41}$ However, in all but two of these studies, ${ }^{24,41}$ TDF use was associated with either increased renal risk or greater reduction in eGFR compared with non-TDF users. It is possible that differences between our study results and those of other studies could have resulted from the definition of renal impairment we applied. The largest cohort analysis was a Center for Disease Control-sponsored evaluation of medical records of $9535 \mathrm{HIV}$-infected persons receiving HAART in $10 \mathrm{US}$ cities during 2000-2003, from whom 34,814 six-month person-observations were made (3489 [10\%] from TDF users and 31,325 [90\%] from non-TDF users). ${ }^{15}$ Multivariate analysis after 1.5 years (median) of follow-up showed that TDF use increased renal impairment risk (defined in the study as an eGFR decrease to $<90 \mathrm{~mL} / \mathrm{min}$ ) by 1.6 fold, as did hypertension by 1.5 -fold, congestive heart failure by 1.9-fold, hemoglobin $(<8 \mathrm{mg} / \mathrm{dL})$ by 4.7 -fold, and CD4+ cell count $\left(<50\right.$ cells $\left./ \mathrm{mm}^{3}\right)$ by 1.5 -fold. Gender, viral load ( $>100,000$ copies $/ \mathrm{mL}$ ), diabetes, wasting syndrome, and weight loss ( $>10$ pounds or $10 \%)$ did not notably affect renal risk. ${ }^{15}$ In the large French ANRS CO3 Aquitaine Cohort in 2588 HIV-infected patients in whom the median baseline CG-calculated eGFR was $96 \mathrm{~mL} / \mathrm{min} / 1.73 \mathrm{~m}^{2}$, multivariate analysis showed that the occurrence of eGFR $<80 \mathrm{~mL} / \mathrm{min} / 1.73 \mathrm{~m}^{2}$ was increased significantly by age $>50$ years compared with younger age groups (odds ratio $[\mathrm{OR}]=13.3, P<0.0001)$, age $41-50$ years compared with younger age groups $(\mathrm{OR}=2.5, P<0.0001)$, baseline body mass index $<22(\mathrm{OR}=3.8, P<0.0001)$, female gender (OR $=3.2, P<0.0001)$, and TDF use for at least one year $(\mathrm{OR}=1.6, P=0.0016) .{ }^{16}$ The Swiss HIV Cohort study compared time to a $10-\mathrm{mL} / \mathrm{min} / 1.73 \mathrm{~m}^{2}$ reduction in CGestimated eGFR over 24 months in treatment-naïve patients or patients with treatment interruptions $\geq 12$ months after starting either a TDF-based combination antiretroviral therapy $(n=363)$ or a TDF-sparing regimen $(n=715) .{ }^{13}$ In the multiple Cox model, the risk of reaching the primary endpoint was increased most notably by concurrent diagnosis of diabetes mellitus (hazard ratio $[\mathrm{HR}]=2.3, P=0.008$ ), TDF use $(\mathrm{HR}=1.8, P=0.0001)$ and boosted protease inhibitor use $(\mathrm{HR}=1.7, P=0.0001)$.

EuroSIDA, a large cohort study in 6843 HIV-positive people in Europe, determined factors that affect the onset of chronic kidney disease. ${ }^{29}$ Chronic kidney disease was defined as either confirmed (at least three months apart) eGFR of $60 \mathrm{~mL} / \mathrm{min} / 1.73 \mathrm{~m}^{2}$ or less for patients with baseline eGFR of 
above $60 \mathrm{~mL} / \mathrm{min}$ per $1.73 \mathrm{~m}^{2}$ or a confirmed $25 \%$ decline in eGFR for patients with baseline eGFR of $60 \mathrm{~mL} / \mathrm{min} / 1.73 \mathrm{~m}^{2}$ or less. Poisson regression was used to determine factors associated with chronic kidney disease. Two hundred and twenty-five (3.3\%) people progressed to chronic kidney disease during 21,482 person-years follow-up, ie, an incidence of 1.05 per 100 person-years follow-up (95\% confidence interval [CI] 0.91-1.18); median follow-up was 3.7 years (interquartile range 2.8-5.7). Diagnosis of an AIDS-defining event, female gender, older age, developing diabetes, being hypertensive, and being HCV antibody-positive were all associated with an increased risk of chronic kidney disease. After adjustment for traditional factors associated with chronic kidney disease and other confounding variables, increasing cumulative exposure to TDF (incidence rate ratio [IRR] per year $1.16,95 \%$ CI $1.06-1.25, P<0.0001)$, indinavir (IRR 1.12, 95\% CI 1.06-1.18, $P<0.0001$ ), atazanavir (IRR 1.21, 95\% CI 1.09-1.34, $P=0.0003$ ) and lopinavir/ritonavir (IRR 1.08, 95\% CI 1.01-1.16, $P=0.030$ ) was associated with a significantly increased rate of chronic kidney disease.

Our study examined both CG- and MDRD-estimated eGFR changes because adjustments for body surface area and African American race differ respectively between the CG and MDRD methods. Higher average serum creatinine level (due to increased muscle mass) is one hypothesis for the racial difference. ${ }^{42}$ Our CG-based mean eGFR values consistently exceeded MDRD-based values by about $5-10 \mathrm{~mL} / \mathrm{min} / 1.73 \mathrm{~m}^{2}$. This magnitude of discordance between the two methods of estimating eGFR has been reported previously, ${ }^{43}$ and occasionally when both CG- and MDRD-based estimations have been used to evaluate renal function in the same population, one method has suggested an increase from baseline in eGFR and the other suggested a decrease. ${ }^{39}$ With each method of assessing eGFR, time on study was observed as a significant risk for renal impairment. However, age and weight only were significant risks according to the CG-estimated eGFR calculation method, as was hypertension only by the MDRD method. This underscores the fact that using different methods of calculating eGFR can lead to different risk assessment results. Indeed, the Swiss HIV Cohort Study found general consistency between CG- and MDRD-calculated risk factors for renal impairment (defined as time to a $10 \mathrm{~mL} / \mathrm{min} / 1.73 \mathrm{~m}^{2}$ reduction in eGFR), but, as in our study, notable discrepancies in risk factors were observable between the CG and MDRD calculation methods. The Swiss HIV Cohort found female gender and diabetes to be significant risk factors only by $\mathrm{CG}$ and presence of elevated systolic blood pressure and presence of AIDS only by MDRD. ${ }^{13}$

Because we did not assess renal tubular dysfunction or proteinuria in our study, this limited our ability to obtain a more complete picture of the renal condition of the study patients. Findings of other studies that did look at tubular status, by examining additional parameters such as spot-urine protein creatinine ratio and 24-hour markers of kidney tubulopathy (glycosuria, hyperaminoaciduria, hyperphosphaturia, and urinary $\beta_{2}$-microglobulinuria), suggest that eGFR alone may not predict other pathology occurring in the kidney. ${ }^{41,44-46}$ Thus, in the Swiss HIV Cohort study ( $\mathrm{n}=1202)$, although TDF use was associated with only a mild to moderate decrease in eGFR, logistic multivariable regression analysis showed that TDF treatment in the absence of a concurrent protease inhibitor was associated with a 3.3-fold higher risk of proximal renal tubulopathy $(P=0.001) .{ }^{47}$ Another limitation of our study was that the sample was not large enough to discern statistical differences between African American, Hispanic, and Caucasian subpopulations.

In conclusion, our retrospective database study in a predominantly African American/Hispanic cohort showed time on study, hypertension, weight, and age to be the only significant predictors of an eGFR decrease $>25 \%$ from baseline.

\section{Acknowledgments}

The authors prepared this paper on behalf of the COL109413 Study Team. They gratefully acknowledge the contributions of the study participants and staff members at the Peabody Health Center to this research. We especially thank Brian C Wine for his statistical programming work.

\section{Disclosure}

The results of this study were presented in part in abstract/ poster form at the 17 th International AIDS Conference, Mexico City, Mexico, August 3-8, 2008. This study was funded by GlaxoSmithKline.

\section{References}

1. Effros RB, Fletcher CV, Gebo K, et al. Aging and infectious diseases: Workshop on HIV infection and aging; what is known and future research directions. Clin Infect Dis. 2008;47:542-553.

2. Gebo KA. HIV and aging. Implications for patient management. Drugs Aging. 2006;23:897-913.

3. American Diabetes Association. African Americans and Complications. Available at: http://www.diabetes.org/living-with-diabetes/complications/ African-americans-and-complications. Accessed 2010 Mar 12.

4. Gupta SK, Eustace JA, Winston JA, et al. Guidelines for the management of chronic kidney disease in HIV-infected patients: Recommendations of the HIV Medicine Association of the Infectious Diseases Society of America. Clin Infect Dis. 2005;40: $1559-1585$. 
5. Centers for Disease Control and Prevention. HIV/AIDS Surveillance Report, 2007. Cases of HIV Infection and AIDS in the United States and Dependent Areas. Vol. 19. Atlanta, GA: US Department of Health and Human Services, Centers, Centers for Disease Control and Prevention; 2009. Available at: http://www.cdc.gov/hiv/topics/surveillance/ resources/reports/. Accessed 2009 Dec 7.

6. National Diabetes Surveillance System. Incidence of diabetes. CSC (online). Available at: http://www.cdc.gov/diabetes/statistics/incidence/ table6.htm. Accessed 2009 Dec 14.

7. Centers for Disease Control and Prevention (CDC). Racial/ethnic disparities in prevalence, treatment, and control of hypertension: United States, 1999-2002. MMWR Morb Mortal Wkly Rep. 2005;54:7-9.

8. Centers for Disease Control and Prevention. National diabetes fact sheet: General information and national estimates on diabetes in the United States, 2007. Atlanta, GA: US Department of Health and Human Services, Centers for Disease Control and Prevention, 2008. Available at: http://www.diabetes.org/uedocuments/NationalDiabetesFactSheetRev. pdf. Accessed 2010 Mar 12.

9. Wyatt CM. HIV and the kidney: A spotlight on racial disparities. J Infect Dis. 2008;197:1490-1492.

10. US Department of Health and Human Services. The Office of Minority Health Hispanic/Latino Profile. 2009 Oct 21. Available at: http:/ minorityhealth.hhs.gov/templates/browse.aspx?1vl=2\&lvlID $=54$ Accessed 2009 Jan 1.

11. Chiapella AP, Feldman HI. Renal failure among male Hispanics in the United States. Am J Publ Health. 1995;85:1001-1004.

12. Lindeman RD, Romero LJ, Yau CL, Baumgartner RN, Garry PJ. Prevalence of mild impairment in renal function in a random sample of elders from a biethnic community survey. Int Urol Nephrol. 2002;33: 553-557.

13. Fux CA, Simcock M, Wolbers M, et al. Tenofovir use is associated with a reduction in calculated glomerular filtration rates in the Swiss HIV Cohort Study. Antivir Ther. 2007;12:1165-1173.

14. Guaraldi, G, Roverato A, Giovanardi C, et al. Glomerular filtration rates in HIV-infected patients treated with and without tenofovir: A prospective, observational study. J Antimicrob Chemother. 2009;63:374-379.

15. Heffelfinger J, Hanson D, Voetsch A, et al. Renal impairment associated with the use of tenofovir. Poster 779 presented at the 13th Conference on Retroviruses and Opportunistic Infections, Denver, CO, 2006 Feb 5-9.

16. Morlat PJM, Deti E, Lawson-Ayayi S, et al. Prevalence and factors associated with renal failure in HIV infected patients, ANRS CO3 Aquitaine Cohort, France. Abstract MOPEB066 presented at the 4th International AIDS Society Conference on HIV Pathogenesis, Treatment and Prevention, Sydney, Australia, 2007 Jul 22-25.

17. Polk C, Uche A, Oursler KA, Reisler RB. Comparing renal function declines in tenofovir and abacavir based regimens in a predominately African-American cohort of men. Poster H-383 presented at the 47th Interscience Conference on Antimicrobial Agents and Chemotherapy, Chicago, IL, 2007 Sep 17-20.

18. Post FA, Campbell LJ, Hamzah L, et al. Predictors of renal outcome in HIV-associated nephropathy. Clin Infect Dis. 2008;46:1282-1289.

19. Reid A, Stöhr W, Walker AS, et al. Severe renal dysfunction and risk factors associated with renal impairment in HIV-infected adults in Africa initiating antiretroviral therapy. Clin Infect Dis. 2008;46:1271-1281.

20. Reisler R, Jacobson L, Gupta S, et al. Chronic kidney disease and the use of HAART. Abstract 818 presented at the 12th Conference on Retroviruses and Opportunistic Infections, Boston, MA, 2005 Feb $22-25$.

21. Short W, Solari P, Kaplan B. Comparison of renal function in a cohort of patients on tenofovir (TDF) versus non-tenofovir containing regimens. Abstract THPE0202 presented at the XVII International AIDS Conference, Mexico City, Mexico, 2008 Aug 3-8.

22. Smith C, Nelson M, Fisher M, et al. Comparison of efficacy and toxicity profile of abacavir (ABA) and tenofovir (TDF) containing regimens. Abstract P1150 presented at the 8th International Congress on Drug Therapy in HIV Infection, Glasgow, UK, 2006 Nov 12-16.
23. Thompson M, Haubrich R, Margolis D, et al. Differences in calculated glomerular filtration rates in efavirenz- or tenofovir-treated adults in ESS40006. Poster 777 presented at the 13th Conference on Retroviruses and Opportunistic Infections, Denver, CO, 2006 Feb 5-8.

24. Tordato F, Cicconi P, Bongiovanni M, et al. Evaluation of renal function in $316 \mathrm{HIV}$-infected patients. Abstract P147 presented at the 8th International Congress on Drug Therapy in HIV Infection, Glasgow, UK, 2006 Nov 12-16.

25. Wolf F, Gunturu G, Koegl C, et al. Tenofovir (TDF)- versus nonTDF-containing ART: Renal toxicity in daily practice. Abstract P153 presented at the 8th International Congress on Drug Therapy in HIV Infection, Glasgow, UK, 2006 Nov 12-16.

26. Wyatt CM, Arons RR, Klotman PE, Klotman ME. Acute renal failure in hospitalized patients with HIV: Risk factors and impact on in-hospital mortality. AIDS. 2006;20:561-565.

27. Young, B, Buchacz K, Baker RK, et al. HIV Outpatient Study Investigators. Renal function in tenofovir-exposed and tenofovir-unexposed patients receiving highly active antiretroviral therapy in the HIV Outpatient Study. J Int Assoc Physicians AIDS Care. 2007;6:178-187.

28. Izzedine H, Harris M, Perazella MA. The nephrotoxic effects of HAART. Nat Rev Nephrol. 2009;5:563-573.

29. Mocroft A, Kirk O, Reiss P, et al. Estimated glomerular filtration rate, chronic kidney disease and antiretroviral drug use in HIV-positive patients. AIDS. 2010;24:1667-1668.

30. Cockcroft DW, Gault MH. Prediction of creatinine clearance from serum creatinine. Nephron. 1976;16:31-41.

31. Levey A, Bosch J, Lewis JB, Greene T, Rogers N, Roth D. A more accurate method to estimate glomerular filtration rate from serum creatinine: a new prediction equation. Ann Intern Med. 1999;130:461-470.

32. Cargill V, Fenton KA. The epidemiology, prevention, and control of HIV/AIDS among African Americans. In: Stone V, Ojikutu B, Rawlings MK, Smith KY, editors. HIV/AIDS in US Communities of Color. New York, NY: Springer Science + Business Media, LLC; 2009.

33. Martorell C. HIV/AIDS and the Latino populations in the US: Epidemiology, prevention, and barriers to care and treatment. In: Stone V, Ojikutu B, Rawlings MK, Smith KY, editors. HIV/AIDS in US Communities of Color. New York, NY: Springer Science + Business Media, LLC; 2009.

34. Betjes MG, Verhagen DW. Stable improvement of renal function after initiation of highly active antiretroviral therapy in patients with HIV-1associated nephropathy. Nephrol Dial Transplant. 2002;17:1836-1839.

35. Chemlal K, Nochy D, Kenouch S, et al. Dramatic improvement of renal function after initiation of highly active antiretroviral therapy. Clin Infect Dis. 2000;31:805-806.

36. Wali RK, Drachenberg CI, Papadimitriou JC, et al. HIV-1-associated nephropathy and response to highly-active antiretroviral therapy. Lancet. 1998;352:783-784.

37. Kirchner JT. Resolution of renal failure after initiation of HAART: 3 cases and a discussion of the literature. AIDS Read. 2002;12:103-5, $110-112$.

38. Szczech LA, Edwards LJ, Sanders LL, et al. Protease inhibitors are associated with a slowed progression of HIV-related renal diseases. Clin Nephrol. 2002;57:336-341.

39. Kamajian R, Machekano R, Crane H, et al. HAART is associated with improved kidney function in patients with impaired kidney function at baseline but was associated with slight worsening of kidney function in patients with normal baseline kidney function. Abstract 735 presented at the 17th Conference on Retroviruses and Opportunistic Infections, San Francisco, CA, 2010 Feb 16-19.

40. Lucas G, Lau B, Atta M, Fine D, Keruly J, Moore R. Chronic kidney disease (CKD) incidence and progression to end-stage renal disease (ESRD) in HIV-infected individuals: A tale of two races. Presented at the 15th Conference on Retroviruses and Opportunistic Infections, Boston, MA, 2008 Feb 3-6.

41. Gardner LI, Holmberg SD, Williamson JM, et al. Development of proteinuria or elevated serum creatinine and mortality in HIV-infected women. J Acquir Immune Defic Syndr. 2003;32:203-209. 
42. Becker S, Balu R, Fusco J. Beyond serum creatinine: Identification of renal insufficiency using glomerular filtration; implications for clinical research and care. Abstract 819 presented at the 12th Conference on Retroviruses and Opportunistic Infections, Boston, MA, 2005 Feb 22-25.

43. Wargo KA, Eiland III EH, Hamm W, English TM, Phillippe HM. Comparison of the Modification of Diet in Renal Disease and Cockcroft-Gault equations for antimicrobial dosage adjustments. Ann Pharmacother. 2006;40:1248-1253.

44. Vanig T, Liao Q, Ha B, Williams C; on behalf of the COL110154 Study Team. Tenofovir effect on renal function factoring in both MDRD-calculated glomerular filtration rate (GFR) and spot urine protein-to-creatinine (UPC) ratio. Poster $96 \mathrm{E}$ presented at the Annual Meeting of the American College of Clinical Pharmacy, Louisville, KY, 2008 Oct 19-22.
45. Labarga P, Barreiro P, Martin-Carbonero L, et al. Kidney tubular abnormalities in the absence of impaired glomerular function in HIV patients treated with tenofovir. AIDS. 2009;23:689-96.

46. Gatanaga $H$, Tachikawa N, Kikuchi Y, et al. Urinary $\beta_{2}$-microglobulin as a possible sensitive marker for renal injury caused by tenofovir disoproxil fumarate. AIDS Res Hum Retrovir. 2006;22: 744-748.

47. Fux CA, Opravil M, Cavassini M, et al. Tenofovir and protease inhibitor use are associated with an increased prevalence of proximal renal tubular dysfunction in the Swiss HIV Cohort Study (SHCS). Poster 743 presented at the 16th Conference on Retroviruses and Opportunistic Infections, Montréal, Canada, 2009 Feb 8-11.

\section{Publish your work in this journal}

HIV/AIDS - Research and Palliative Care is an international, peerreviewed open-access journal focusing on advances in research in HIV, its clinical progression and management options including antiviral treatment, palliative care and public healthcare policies to control viral spread. The journal welcomes original research, basic science, clinical \& epidemiological studies, reviews \& evaluations, expert opinion \& commentary, case reports \& extended reports. The manuscript management system is completely online and includes a very quick and fair peer-review system. Visit http://www.dovepress. com/testimonials.php to read real quotes from published authors. 